\title{
A Study on Anti-Kong Xiangxi Movement in the Rear Area during the Anti-Japanese War
}

\author{
Xinglin Peng \\ Chongqing Youth Vocational and Technical College, Chongqing, 400712, China
}

Key words: During the Anti-Japanese War, Anti-Kong Xiangxi movement, Student movement.

\begin{abstract}
During the Anti-Japanese War, college students who were edified by advanced culture and theories went into political struggle one after another, becoming an essential force. This paper is written to analyze the cause of "Anti-Kong Xiangxi Movement" in the rear area during the Anti-Japanese War, review the whole story and result, and explore the historical significance and enlightenment of this movement from four aspects.
\end{abstract}

\section{Introduction}

During the Anti-Japanese War, China went short of goods and materials, the Kuo Min Tang (KMT) became increasingly autarchic and dictatorial, and fascists led by the Japanese army pressed the country step by step. Facing the internal disorder and foreign invasions, Chinese people woke up and rose up in resistance, having launched a series of protests and campaigns. The group of students also turned to fighting, becoming a major force in the Anti-Japanese War. Besides the May 4th Movement in 1919, the "Anti-Kong Xiangxi Movement" launched by college students in cities in the rear area of Anti-Japanese War since 1942 demonstrated the advancement and unity of students again[1], but also revealed the limitations of student movement. This Movement ended with a failure, but it was of great historical significance, and enlightened later generations.

\section{Causes}

\section{Sharpening Social Contradiction}

In the initial period of the Anti-Japanese War, most universities moved to inland areas to avoid damage of war, and students also moved with universities. Since the Southern Anhui Incident, the KMT had become more and more autarchic and dictatorial, cruelly persecuting and oppressing the advanced intelligentsia and stringently controlling college students who received advanced ideas by prohibiting students from reading philosophical books, tracking down and arresting progressive teachers and students suspected of colluding with Chinese Communist Party, and monitoring advancement campaigns organized by schools. All these had caused resentment. Due to education budget shortage, the living, study and working of teachers and students of the National South-west Associated University consisting of Peking University, Tsinghua University and Nankai University couldn't be guaranteed. What's worse, the KMT government implemented bad military, economic and political policies. The social contradictions were intensified. The public including students in the rear area resented the authority of KMT, and the contradictions between students and the government were on the verge of breaking out, which sew the seeds of "Anti-Kong Xiangxi Movement".

\section{Students Developing An Operation Sense}

During the Anti-Japanese War, fierce military war was proceeding in the battlefield, and political battles were running in the rear area. Students who were influenced by advanced ideas had sensitive democratic consciousness; they were well educated, sensitive to the society, and liable to be aware of the malpractice of KMT in military, political, cultural and economic policies, and realized that they had to struggle for hopes; being bold and adventurous, youthful students stood up against irrationality and unfairness. Since the May 4th Movement, students had been denouncing the corruptions of the 
government in various ways, arousing sympathy in teachers and students, and more and more students threw themselves into democratic movement. During the "Anti-Kong Xiangxi Movement", the consciousness of resisting autarchy and fighting for democracy had penetrated deeply into people's minds for a long time, and students reached a consensus of launching a national salvation movement. Being unarmed, students had no choice but resorting to demonstration to urge the KMT government to listen to students' dissuasion in a peaceful way.

\section{Government Control Weakening}

To put college education under its control, the KMT government implemented the policy of ruling colleges by a political party. Chen Lifu carried out party and league work through professors. Professors and historiographers of the National South-west Associated University led by Yao Congwu founded a branch directly subordinate to the Three People's Principles Youth League in the university, for the purpose of controlling students. Since the students had been influenced by democratic ideas, and the concepts of democracy and freedom had penetrated deeply into people's minds, the educational idea of the KMT government was boycotted by universities and students. Besides, the KMT government issued no mandatory order to restrict the actions and activities of universities, teachers and students, such as professor employment, recruitment, academic research. Thus, the party-oriented education pushed by the KMT government in universities appeared to be loose, which didn't consolidate the control power of the government.

\section{Blasting Fuse of" Anti-Kong Xiangxi Movement"}

In December 1941, the Pacific War broke out, Hong Kong was attacked and occupied by Japanese army, and many intelligentsia got stuck in Hong Kong with their lives were threatened. Professor Chen Yinque who enjoyed a high reputation in student and teacher groups also was trapped in Hong Kong, making the students and teachers of the National South-west Associated University anxious[2]. At that time, the minister of finance Kong Xiangxi should transported his private goods such as dog, flush toilet and so on from Hong Kong back to Chongqing by flight, but turned a cold shoulder to the life of those who were trapped in Hong Kong. Upon this event was reported, Kong Xiangxi was strongly condemned. The Ta Kung Pao, Xinmin Bao and Morning Paper etc. published insinuating editorials, directly aiming at Kong's corruption, embezzlement, malpractice and so on. This intensified the resentment on Kong of the public. The public opinions and critique led by students on Kong became the blasting fuse of the first "Anti-Kong Xiangxi Movement". The second "Anti-Kong Xiangxi Movement" occurred in March 1944, when Kong planned to comfort the students of the translation training class, but he changed the meeting place and contents, and was late, arousing great anger of students. The second "Anti-Kong Xiangxi Movement" happened.

\section{Whole Story}

\section{The First "Anti-Kong Xiangxi Movement"}

In December 1941, the incident that Kong transported his dog by flight caused an uproar, and the public unanimously urged the authority to punish Kong. The "crying" wall poster pasted beside the gate of the National South-west Associated University insinuated the embezzlement, corruption and reactionary actions of Kong, striking a chord among the teachers and students. The accompanying "echoing" wall poster and fellow-students meeting, class meeting, grade meeting, department meeting, and school meeting echoed the incident. Thus, within two days after the "crying" wall poster, the walls of dormitory of the university were filled with slogans reading "overthrow Kong Xiangxi", and the hubbub requiring criticizing and denouncing Kong increasingly rose. On the third day after the incident, the students of grade one of Kunhua Middle School launched a demonstration themed by "overthrow Kong Xiangxi, and students from the Chinois-Franco University, other middle schools and even primary schools joined to enhance the parading procession. The Movement gradually spread to other schools around the country, and all schools denounced and condemned Kong, and 
demanded the KMT authority to punish Kong. On the fourth day, under the suppression of the KMT, the students of the Three People's Principles Youth League were reprimanded and changed their tune to hinder other students; Kang Ze created fear and panic via through the special task battalion to suppress the student movement; the secretary general of the Executive Yuan Jiang Menglin required students to stop, which ended the first 4-day "Anti-Kong Xiangxi Movement".

\section{The Second "Anti-Kong Xiangxi Movement"}

The second "Anti-Kong Xiangxi Movement" happened in March 1944. Kong came to Kunming to mediate the dispute between the Soongs and the Chiangs. The authority of the translation training class declared that Kong came to comfort students, and required students to do internal affairs which took a whole day to meet Kong. On the scheduled meeting day, the declared comforting changed into reprimand, and students were forced to head to Yunnan University. Kong didn't show up even after the students had waited for half an hour. The outraged students cried out "overthrow Kong Xiangxi", but were reprimanded, which ended the second "Anti-Kong Xiangxi Movement".

\section{Result}

\section{Result of the National South-west Associated University and Students}

The second "Anti-Kong Xiangxi Movement" was nowhere near the first "Anti-Kong Xiangxi Movement" in respect of scale, influence, participants and effect. In this paper, the first "Anti-Kong Xiangxi Movement" was detailed. After the "Anti-Kong Xiangxi Movements", the special task battalion led by Kang Ze drafted out a hit list, and arrested reactionary students, but were prevented by the standing committee of the National South-west Associated University. Thus, the students of the National South-west Associated University were protected, and no sanguinary conflict occurred. The authorities of the KMT denounced that the student movements in the rear area were "flighty and manic", and "hateful", and demanded the Ministry of Education to eliminate those incited by the CCP and rectify the presidents and professors. Meanwhile, Soong Mei-ling gave an admonitory talk to students of the National South-west Associated University and Yunnan University, argued that she and Soong Ai-ling had no pet dog, denied the incident of transporting dog by flight, and reprimanded students.

\section{Result of Kong Xiangxi}

After the "Anti-Kong Xiangxi Movements" ended, Chiang Kai-shek dismissed Kong Xiangxi from his post of president of the Central Bank and vice-president of the Executive Yuan, and didn't punish Kong for his corruption and embezzlement; and sent Kong to America for the International Monetary Conference to avoid the rising Anti-Kong Xiangxi tide. Besides, Chiang investigated the corruption of the high management of the Central Bank thoroughly, and rectified the Central Bank. The curtain of the "Anti-Kong Xiangxi Movements" fell.

\section{Historical Significance}

\section{Positivity}

The "Anti-Kong Xiangxi Movements" were another reflection of advancement of students after the May 4th Movement, and established the status of students in Anti-Japanese War that cannot be ignored. In the movements, students and other classes understood the corruption of the KMT more profoundly, and realized the importance of political reform and democracy. The underground 
workers of the CCP also participated in the movements, and frequently contacted with students, bringing advanced idea to students and laying a foundation for the development of the CCP in student group. Chiang Kai-shek, upon the requests of students, investigated the corruption of the high management of the Central Bank, and punished some officers who committed embezzlement, meting the requirements of the public for fighting against corruption and embezzlement to a certain extent[3].

\section{Negativity}

The movements made the KMT be aware of that they should control college students more tightly, and then they did so by reorganizing the special task battalion and suppressing advanced activities. The KMT suspected that someone(s) from the advanced groups such as the CCP, National Socialist Party, etc. planned the movements, and kept close watch over many advanced CCP members, which hindered their actions for a period.

\section{Limitation}

The outburst of the movements revealed the defects and limitations of student movements. Firstly, the movement was launched by students, and few participants came from other classes. The student group were relatively weak for action. Though the underground workers of the CCP participated the movement, they didn't act as leader. Besides, the movement was burst out without any rigorous planning in advance, so that the failure had already doomed. Secondly, students launched the Movement aiming at the embezzlement and corruption of Kong Xiangxi rather than the political system of the KMT, but still recognized the legality of the KMT government, so the movement was limited[4]. Besides, students believed that the corruption and embezzlement caused the economic and political disorder in the rear area, and didn't get clear about the primary cause. Thirdly, the requests of "overthrow Kong Xiangxi" and "political reform" of students received no response from the KMT government, and Chiang Kai-shek just dismissed the post of Kong, and investigated the corruption and embezzlement of high management of the Central Bank, which was of no material significance. To sum up, the "Anti-Kong Xiangxi Movements" were limited.

\section{Enlightenment of the Movement}

The "Anti-Kong Xiangxi Movements" were launched by students. The CCP realized the effective strength of students in political struggle, and turned to depend on students to enhance their force. The failure of the "'Anti-Kong Xiangxi Movements" rested in the limitation and unthoroughness of student movement. This implied that all walks of life can be mobilized and united. The Movements left valuable experience and lessons to the following movements organized by students, workers and the CCP. The failure taught us that we should make well preparations before doing anything, including objectives, methods, guidelines and activity plan, so that we can defend our fruits.

\section{Conclusion}

"Anti-Kong Xiangxi Movement" was one of the resistance movements during the Anti-Japanese War, but it greatly influenced the development of life and society at that time. The occurrence of the movement was occasional and also inevitable, because the decayed ruling of the KMT was unsatisfactory and even hateful. The movement left valuable experience to us, and trained a young and energetic force, speeding up the growth of students in the Anti-Japanese War.

\section{References}

[1] Ye Yunling. Historical Retrospection and Outlook on Student Movement in China, The Party Building and Ideological Education in Schools, 2016(05):65-67.

[2] Cao Xinbao. A Study of Zhejiang University on "Anti-Kong Xiangxi Movement" in Zunyi, Chinese and Foreign Entrepreneurs, 2014 (12): 256-257. 
[3] Wu Jinqi. "Anti-Kong Xiangxi Movement": Contentious Politics during the Anti-Japanese War, Oriental Forum, 2013 (06): 34-41.

[4] Zheng Huixin. "Anti-Kong Xiangxi Movement" in the Rear Area during the Anti-Japanese War, Lanzhou Academic Journal, 2015 (12): 1-11. 